\title{
Evaluation of coronary artery disease in patients with atrial fibrillation by cardiac computed tomography for catheter ablation: CADAF-CT trial
}

\author{
Takahiro Mito $\cdot$ Masao Takemoto ${ }^{1,2}$ (1) $\cdot$ Yoshibumi Antoku ${ }^{1} \cdot$ Akihiro Masumoto $^{3} \cdot$ Masatsugu Nozoe $^{4}$. \\ Satoko Kinoshita ${ }^{1} \cdot$ Atsushi Tanaka $^{1} \cdot$ Yusuke Yamamoto $^{4} \cdot$ Takafumi Ueno $^{3} \cdot$ Takuya Tsuchihashi $^{2}$
}

Received: 9 September 2019 / Accepted: 21 February 2020 / Published online: 5 March 2020

(c) The Author(s) 2020

\begin{abstract}
Almost all institutions routinely perform cardiac computed tomography (CT) before radiofrequency catheter ablation (RFCA) of atrial fibrillation (AF) to evaluate the cardiac anatomy. The ideal timing of the CT image acquisition is different between for RFCA of AF and for evaluation of coronary artery lesions (CALs). Thus, the aim of this study was to assess whether 64- or 320-line routine cardiac CT scans before RFCA of AF could evaluate both coronary artery lesions and pulmonary veins (LA-PVs) anatomy at the timing of the image acquisition of the LA-PVs in patients with AF who underwent RFCA of AF. The CALs were evaluated in 606 consecutive patients who underwent RFCA of AF assessed by the ideal timing of the $\mathrm{CT}$ image acquisition for RFCA of AF, and myocardial ischemia (MI) was also evaluated in patients with severe coronary stenosis $(\geq 50 \%)$ and unevaluable CALs due to their severe coronary calcification and banding artifact by additional examinations combined with exercise stress testing, ${ }^{201} \mathrm{Tl}$ scintigraphy, and/or fractionated flow reserve measurements. This study revealed that, in patients with AF who underwent RFCA of AF, (1) both 64- and 320-line cardiac CT scans for RFCA of AF could evaluate CALs in $93 \%$ of those patients, (2) the prevalence of MI was $9 \%$, (3) significant relationships between the $\mathrm{CHADS}_{2}$ score and prevalence of MI were observed $(p=0.003)$, and (4) the positive predict values of MI in patients with severe coronary stenosis $(\geq 50 \%)$ and unevaluable CALs also significantly increased in accordance with the CHADS $_{2}$ score $(p=0.003)$. The evaluation of CALs and MI by routine cardiac CT for RFCA of AF combined with the additional examinations may be one of the most feasible modalities for patients with AF.
\end{abstract}

Keywords Atrial fibrillation · Catheter ablation $\cdot \mathrm{CHADS}_{2}$ score $\cdot$ Computed tomography $\cdot$ Coronary artery disease $\cdot$ Myocardial ischemia

Takahiro Mito, Yoshibumi Antoku, Akihiro Masumoto, and

Masatsugu Nozoe have contributed equally to this paper.

Masao Takemoto

matakemo@kc4.so-net.ne.jp;

matakemo@cardiol.med.kyushu-u.ac.jp

1 Cardiology, Munakata Suikokai General Hospital, Fukutsu, Japan

2 Cardiovascular Center, Steel Memorial Yawata Hospital, 1-1-1 Haruno-machi, Yahatahigashi-ku, Kitakyushu 805-8508, Japan

3 Cardiology, Fukuoka Kinen Hospital, Fukuoka, Japan

4 Cardiology, Saiseikai Fukuoka General Hospital, Fukuoka, Japan

\author{
Abbreviations \\ AF Atrial fibrillation \\ BMI Body mass index \\ CAG Coronary angiography \\ CAD Coronary artery disease \\ CT Computed tomography \\ FFR Fractionated flow reserve \\ RFCA Radiofrequency catheter ablation
}

\section{Introduction}

The number of patients with atrial fibrillation (AF) has been increasing, and radiofrequency catheter ablation (RFCA) of AF has proven to be a useful strategy worldwide [1]. The $\mathrm{CHADS}_{2}$ score is well known to be a useful predictor of the risk for not only cerebral infarctions associated with $\mathrm{AF}$ 
[2], but also a new onset of AF [3]. Moreover, the CHADS 2 score is constructed by risk factors of coronary artery disease (CAD), and has also been reported as a predictor of cardiovascular/cerebrovascular events in patients with $\mathrm{CAD}$ without $\mathrm{AF}[4,5]$. The close relationship between $\mathrm{AF}$ and $\mathrm{CAD}$ has been reported [6], and that (1) the prevalence of CAD detected by coronary computed tomography (CT) is significantly higher in patients with $\mathrm{AF}$ than in those without [7], and (2) coronary angiography (CAG) can detect coronary narrowing $(\geq 50 \%)$ in patients with $\mathrm{AF}$ who undergo RFCA of AF [8]. Almost all institutions routinely perform cardiac CT before RFCA of AF to evaluate the cardiac anatomy, especially of the left atrium and pulmonary veins (LA-PVs). The ideal timing of the CT image acquisition is different between the LA-PVs and coronary arteries. For example, the imagings which were the ideal timings of the image acquisition of LA-PVs or coronary arteries starts after confirming the pulmonary arteries or ascending aorta have been contrasted by visual observation, respectively. Thus, the aim of this study was to assess whether 64- or 320-line routine cardiac CT scans before RFCA of AF could evaluate both coronary artery lesions and LA-PVs anatomy at the timing of the image acquisition of LA-PVs in patients with AF who underwent RFCA of AF.

\section{Materials and methods}

\section{Study population and laboratory analysis}

This study was approved by the institutional review committee and ethics review board of our hospitals. From April 2016 to June 2018, 606 consecutive patients (402 males and 204 females with a mean age of $69 \pm 0.4$ years and body surface area of $1.68 \pm 0.01 \mathrm{~m}^{2}$ ) (Table 1) with AF and without previous histories of CAD who were admitted to our hospitals to undergo RFCA of AF were evaluated. The type of AF was determined according to the 2011 ACC/AHA/ ESC guidelines for the management of patients with AF [9]. Patients that could not use contrast because of renal dysfunction (serum creatinine $\geq 1.5 \mathrm{mg} / \mathrm{dL}$ ) and that underwent hemodialysis were excluded. All patients had their history recorded and underwent a physical examination and laboratory analysis.

\section{Computed tomography}

All patients gave written informed consent before imaging. The imaging technique has been described previously [10]. In brief, after sublingual administration of $0.3 \mathrm{mg}$ of nitroglycerin, following a test bolus, $50-60 \mathrm{ml}$ of nonionic contrast medium (Omnipaque 300, Amersham Health, Oslo, Norway) was injected at $20-22 \mathrm{mgI} / \mathrm{kg} / \mathrm{s}$ via an antecubital vein. The imaging which was the ideal timing of the image acquisition of LA-PVs started after confirming the pulmonary arteries had been contrasted by visual observation. Scanning was performed in a single breath hold in the cranio-caudal direction at the level of the aortic arch using a simultaneous acquisition of eight sections (each $0.5 \mathrm{~mm}$ ), with a prospective electrocardiogram (ECG)triggering set at $75 \%$ of the RR interval, beam collimation of $10 \mathrm{~mm}$, and table speed $16.75 \mathrm{~mm} / 0.5 \mathrm{~s}$ or fixed table $(0.5$ or $0.275 \mathrm{~s}$ tube rotation time, $120 \mathrm{kV}, 500 \mathrm{~mA}$, or $750 \mathrm{~mA}$ ) by 64 -line or 320 -line CT scans. Contiguous $0.5 \mathrm{~mm}$ axial CT (Aquilion, 64-line, 320-line, TOSHIBA, Tokyo, Japan) slices were reconstructed from the CT data using a soft-tissue algorithm and the resulting DICOM data were recorded onto a CD-ROM. When the patients' heart rate was more than $70 \mathrm{bpm}$, the oral administration of $20 \mathrm{mg}$ of the beta-blocker metoprolol tartrate and/or $0.5 \mathrm{mg}$ of the minor tranquilizer etizolam were used.

\section{Evaluation of coronary artery lesions by cardiac CT and the detection of myocardial ischemia}

The coronary lesions were evaluated in all patients who underwent cardiac CT scans at the timing of the image acquisition of LA-PVs for RFCA of AF. Mild-to-moderate and severe stenoses were defined as $\leq 50 \%$ and $>50 \%$ stenosis, respectively. Unevaluable coronary artery lesions were defined as severe coronary calcifications and/or banding artifacts [11] that made the evaluation of the coronary artery lesions impossible. The patients with severe coronary stenosis ( $>50 \%)$ and/or unevaluable coronary artery lesions were evaluated for myocardial ischemia before or after the RFCA of AF. To evaluate the myocardial ischemia, they underwent examinations combined with exercise stress testing, ${ }^{201} \mathrm{Tl}$ scintigraphy, and/or fractionated flow reserve (FFR) measurements [12].

\section{Statistical analysis}

The numerical results are expressed in the text as the mean \pm standard deviation. Paired data were compared by a Fisher's exact test and Student's $t$ test. The trend in the proportions and correlation between the prevalence of severe coronary stenosis ( $>50 \%)$, unevaluable coronary artery lesions, or myocardial ischemia and the $\mathrm{CHADS}_{2}$ score was determined by a Cochran-Armitage analysis. All analyses were performed with SAS version 9.2 software (SAS Institute, Cary, NC, USA). A $p$ of $<0.05$ was considered to indicate statistical significance. 
Table 1 Patient characteristics

\begin{tabular}{|c|c|c|c|c|}
\hline & All & 64-line & 320-line & $p$ value \\
\hline$n$ & 606 & $410(68 \%)$ & $196(32 \%)$ & - \\
\hline Male & $408(67 \%)$ & $268(65 \%)$ & $140(71 \%)$ & 0.137 \\
\hline Age (years) & $69 \pm 9.0$ & $69 \pm 9.2$ & $68 \pm 8.4$ & 0.075 \\
\hline Body mass index $\left(\mathrm{kg} / \mathrm{m}^{2}\right)$ & $23.1 \pm 3.5$ & $23.3 \pm 3.5$ & $22.8 \pm 3.6$ & 0.146 \\
\hline Body surface area $\left(\mathrm{m}^{2}\right)$ & $1.68 \pm 0.19$ & $1.67 \pm 0.19$ & $1.69 \pm 0.17$ & 0.082 \\
\hline $\mathrm{CHADS}_{2}$ score & $2.05 \pm 1.29$ & $2.04 \pm 1.30$ & $2.07 \pm 1.29$ & 0.791 \\
\hline 0 & $56(9 \%)$ & $38(9 \%)$ & $18(9 \%)$ & 0.981 \\
\hline 1 & $163(27 \%)$ & $110(27 \%)$ & $53(27 \%)$ & 0.941 \\
\hline 2 & $200(33 \%)$ & $140(34 \%)$ & $60(31 \%)$ & 0.332 \\
\hline 3 & $108(18 \%)$ & $70(17 \%)$ & $38(19 \%)$ & 0.432 \\
\hline 4 & $47(8 \%)$ & $32(8 \%)$ & $15(8 \%)$ & 0.955 \\
\hline$\geq 5$ & $32(5 \%)$ & $20(5 \%)$ & $12(6 \%)$ & 0.430 \\
\hline Congestive heart failure & $293(48 \%)$ & $188(46 \%)$ & $105(54 \%)$ & 0.243 \\
\hline Hypertension & $424(70 \%)$ & $287(70 \%)$ & $137(70 \%)$ & 0.899 \\
\hline Age $(\geq 75$ years old $)$ & $164(27 \%)$ & $122(33 \%)$ & $42(21 \%)$ & 0.053 \\
\hline Diabetes mellitus & $158(26 \%)$ & $107(26 \%)$ & $51(26 \%)$ & 0.941 \\
\hline History of CVA/TIA & $103(17 \%)$ & $66(16 \%)$ & $37(19 \%)$ & 0.255 \\
\hline Dyslipidemia & $200(33 \%)$ & $135(33 \%)$ & $65(33 \%)$ & 0.951 \\
\hline Ex or current smoking & $170(28 \%)$ & $115(28 \%)$ & $55(28 \%)$ & 0.977 \\
\hline \multicolumn{5}{|l|}{ Type of atrial fibrillation } \\
\hline Paroxysmal & $369(61 \%)$ & $240(59 \%)$ & $129(66 \%)$ & 0.086 \\
\hline Persistent & $209(33 \%)$ & $146(36 \%)$ & $62(32 \%)$ & 0.336 \\
\hline Long-lasting & $29(5 \%)$ & $24(6 \%)$ & $5(3 \%)$ & 0.075 \\
\hline \multicolumn{5}{|l|}{ Laboratory analysis } \\
\hline Serum creatinine (mg/dl) & $0.89 \pm 0.24$ & $0.89 \pm 0.24$ & $0.90 \pm 0.23$ & 0.409 \\
\hline Left-ventricular ejection fraction (\%) & $63 \pm 9.9$ & $63 \pm 9.1$ & $64 \pm 11$ & 0.268 \\
\hline Diameter of left atrium (mm) & $39 \pm 6.7$ & $39 \pm 6.6$ & $39 \pm 6.7$ & 0.309 \\
\hline \multicolumn{5}{|l|}{ Parameters during CT imaging } \\
\hline Heart rate (bpm) & $66 \pm 15$ & $66 \pm 15$ & $66 \pm 16$ & 0.829 \\
\hline Sinus rhythm & $398(66 \%)$ & $261(64 \%)$ & $137(70 \%)$ & 0.131 \\
\hline \multicolumn{5}{|l|}{ Medications during CT imaging } \\
\hline Beta-blocker (\%) & $421(69 \%)$ & $293(71 \%)$ & $128(65 \%)$ & 0.124 \\
\hline Minor tranquilizer (\%) & $172(28 \%)$ & $119(29 \%)$ & $52(27 \%)$ & 0.524 \\
\hline
\end{tabular}

CVA cerebrovascular apoplexy, TIA transient ischemic attack, $C T$ computed tomography

\section{Results}

\section{Patient characteristics and laboratory analysis (Table 1)}

Cardiac CT scans for RFCA of AF were performed in 606 patients with AF and without a previous history of CVD at our hospitals. Because three patients did not agree to the use of contrast for the cardiac CT because of their renal dysfunction, they were excluded from the statistical analysis. No patients suffered from any cardiac CT-related complications except for a contrast-induced eruption. In all patients, the mean $\mathrm{CHADS}_{2}$ score was $2.05 \pm 1.29$ points. The numbers of patients were $56(9 \%), 163(27 \%)$, $200(33 \%), 108(18 \%), 47(8 \%)$, and $32(5 \%)$ for those with a $\mathrm{CHADS}_{2}$ score of $0,1,2,3,4$, and $\geq 5$ point(s), respectively. The prevalence of congestive heart failure, hypertension, age over 75 year old, diabetes mellitus, history of cerebrovascular apoplexy/transient ischemic attack, dyslipidemia, ex- or current smoking, paroxysmal $\mathrm{AF}$, persistent $\mathrm{AF}$, and long-lasting $\mathrm{AF}$ was 239 (48\%), 424 (70\%), 164 (27\%), 158 (26\%), 103 (17\%), 200 (33\%), $170(28 \%), 369(61 \%), 209(33 \%)$, and $29(5 \%)$, respectively. The values of the serum creatinine, left-ventricular ejection fraction (LVEF), and diameter of the left atrium (LA) (LAD) by echocardiography were $0.89 \pm 0.24 \mathrm{mg} /$ $\mathrm{dL}, 63 \pm 9.9 \%$, and $39 \pm 6.7 \mathrm{~mm}$, respectively. The mean heart rare and prevalence of sinus rhythm during the CT imaging were $66 \pm 15 \mathrm{bpm}$ and $398(66 \%)$, respectively. The prevalence of the use of beta-blockers and/or minor 
tranquilizers during the CT imaging was $421(69 \%)$ and $172(28 \%)$, respectively.

\section{Evaluation of the coronary artery lesions and myocardial ischemia (Tables 2,3 )}

The amount of the contrast medium and radiation exposure time when evaluating the LA-PV anatomy plus the coronary arteries were the almost same when compared with evaluating the LA-PV anatomy only. They were about $60 \mathrm{ml}$ or $50 \mathrm{ml}$, and $20 \mathrm{~s}$ or $8 \mathrm{~s}$ by 64 -line or 320-line CT scans, respectively. However, the extra time about $15 \mathrm{~min}$ was needed to reconstruction and evaluation of LA-PV anatomy plus the coronary arteries compared to LA-PV anatomy only. The coronary artery lesions in 562 (93\%) out of the 606 patients could be evaluated, but not in the remaining $44(7 \%)$ patients, defined as unevaluable coronary artery lesions, because of severe coronary calcifications $(n=41 ; 7 \%)$ or banding artifact $(n=3 ; 0.5 \%)$. The prevalence of mild-to-moderate $(\leq 50 \%)$, severe stenosis $(>50 \%)$, and unevaluable coronary artery lesions, was 418 (69\%), 144 (24\%), and 44 (7\%), respectively. Myocardial ischemia was evaluated in $188(31 \%)$ patients, including $144(24 \%)$ patients with a $>50 \%$ coronary artery stenosis and $44(7 \%)$ with unevaluable coronary artery lesions by cardiac CT, exercise stress testing $(30 \%),{ }^{201} \mathrm{Tl}$ scintigraphy (14\%), and/or fractionated flow reserve (FFR) measurements [12] (10\%). Finally, myocardial ischemia was detected in 54 (9\%) patients. There were no patients, including both those 144 patients with severe $(>50 \%)$ coronary artery stenosis and the remaining 462 patients, who had major adverse cardiovascular events including acute coronary syndrome and heart failure before, during, and after RFCA of AF. After RFCA of AF, 51 patients out of 54 patients with myocardial ischemia underwent re-vascularization of coronary arteries with percutaneous coronary interventions. Remaining 3 patients with myocardial ischemia were treated by optimal medical therapies.
Table 3 Evaluation and detection of myocardial ischemia

\begin{tabular}{lr}
\hline Evaluation of myocardial ischemia & \\
Number of patients & $188(31 \%)$ \\
Exercise stress testing & $180(30 \%)$ \\
${ }^{201} \mathrm{Tl}$ scintigraphy & $82(14 \%)$ \\
Fractionated flow reserve & $62(10 \%)$ \\
Detection of myocardial ischemia & \\
Number of patients & $54(9 \%)$ \\
\hline
\end{tabular}

\section{Correlation between the $\mathrm{CHADS}_{2}$ score and myocardial ischemia (Fig. 1)}

In accordance with the $\mathrm{CHADS}_{2}$ score, the prevalence of patients with severe coronary stenosis $(>50 \%)(p=0.044)$ and unevaluable coronary artery lesions (blue bar) $(p=0.017)$, and myocardial ischemia (red bar) $(p=0.003)$ has been significantly increasing. Interestingly, in accordance with the $\mathrm{CHADS}_{2}$ score, the positive predict values of myocardial ischemia in patients with severe coronary stenosis $(>50 \%)$ and unevaluable coronary artery lesions also have been significantly increasing $(p=0.003)$.

\section{Comparison between the 64- and 320-line CT (Tables 1, 2)}

The prevalence of the use of a 64- and 320-line CT scans was 410 (68\%) and $196(32 \%)$, respectively. There were no statistical differences in the patient characteristics (Table 1), prevalence of evaluable or unevaluable coronary artery lesions, and prevalence of mild, moderate, and severe coronary artery lesions (Table 2), between the two groups. However, there were only $3(0.5 \%)$ patients with rapid AF (the mean heart rate: $91 \pm 3 \mathrm{bpm}$ ) during the $\mathrm{CT}$ imaging whose coronary artery lesions could not be evaluated by the 64-line scans because of banding artifact [11] due to rapid AF, even though they received beta-blockers and minor tranquilizers (Table 1,2).
Table 2 Evaluation of coronary artery lesions

\begin{tabular}{llcrc}
\hline & All & 64-line & 320-line & $p$ value \\
\hline Number of patients & 606 & $410(68 \%)$ & $196(32 \%)$ & - \\
Coronary arterial stenosis & & & & \\
$\quad$ Evaluable coronary artery lesions & $562(93 \%)$ & $381(93 \%)$ & $181(92 \%)$ & 0.809 \\
$\quad$ Mild-to-moderate $(\leq 50 \%)$ & $418(69 \%)$ & $283(69 \%)$ & $135(69 \%)$ & 0.801 \\
$\quad$ Severe $(>50 \%)$ & $144(24 \%)$ & $98(24 \%)$ & $46(23 \%)$ & 0.818 \\
Unevaluable coronary artery lesions & & & & \\
$\quad$ Severe coronary calcification & $41(7 \%)$ & $26(6 \%)$ & $15(8 \%)$ & 0.548 \\
$\quad$ Banding artifacts & $3(0.5 \%)$ & $3(0.7 \%)$ & $0(0 \%)$ & 0.231 \\
\hline
\end{tabular}




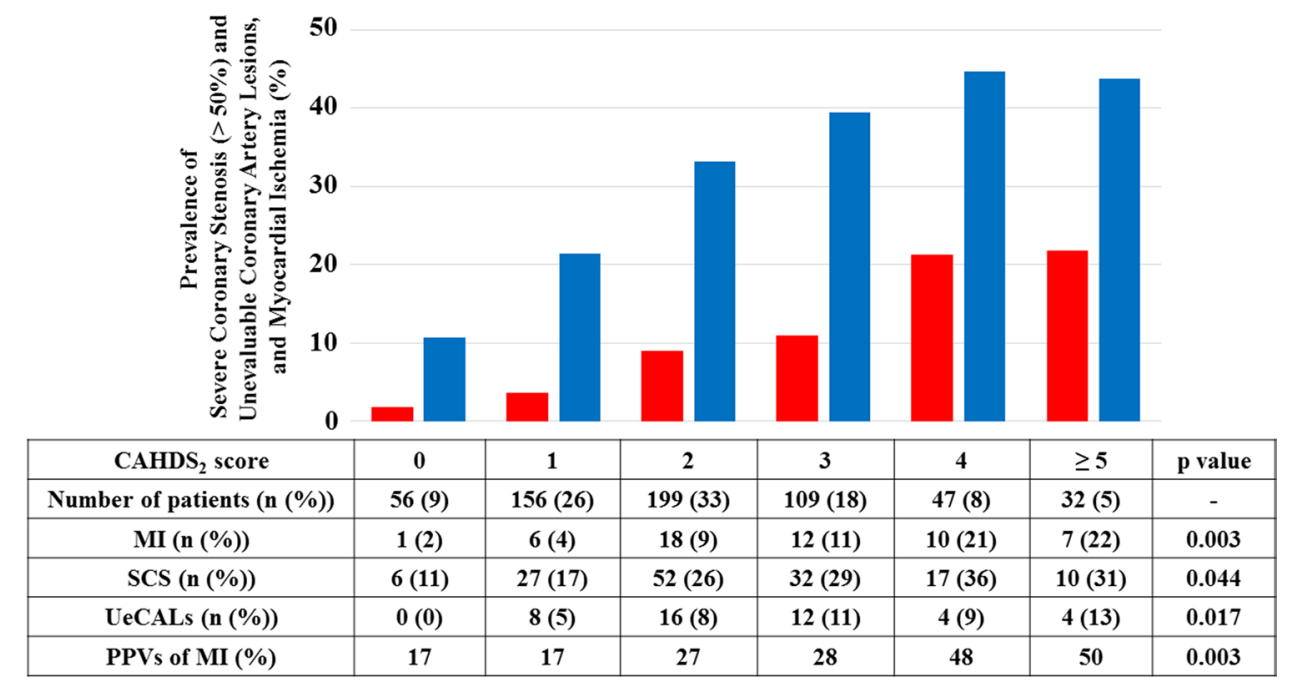

Fig. 1 Prevalence of patients with severe coronary stenosis (SCS) $(>50 \%)$ and unevaluable coronary artery lesions (UeCALs) (blue bar), and myocardial ischemia (MI) (red bar) according to the $\mathrm{CHADS}_{2}$ score. In accordance with the $\mathrm{CHADS}_{2}$ score, the prevalence of those parameters (blue bar; $p=0.033$ and red bar; $p=0.003$ )

\section{Discussion}

This study revealed that, in patients with AF who underwent RFCA of AF, (1) both 64- and 320-line routine cardiac CT scans for RFCA of AF at the timing of the image acquisition of LA-PVs could evaluate coronary artery lesions in $93 \%$ of those patients, (2) the prevalence of myocardial ischemia was $9 \%$, (3) significant relationships between the $\mathrm{CHADS}_{2}$ score and prevalence of severe coronary stenosis (>50\%) and unevaluable coronary artery lesions, and myocardial ischemia were observed, and (4) the positive predict values of myocardial ischemia in patients with severe coronary stenosis $(>50 \%)$ and unevaluable coronary artery lesions also significantly increased in accordance with the $\mathrm{CHADS}_{2}$ score $(p=0.003)$.

\section{Evaluation of the coronary artery lesions by cardiac CT scans for RFCA of AF}

Because the scanning performed during a single breath hold with the prospective ECG-triggering set at $75 \%$ of the RR interval during the cardiac CT imaging, the scanning becomes very difficult during an AF rhythm that has an irregular RR interval and/or tachycardia of more than $100 \mathrm{bpm}$ that has a shorter RR interval [13]. Those conditions sometimes cause banding artifact, which makes it difficult to evaluate coronary artery lesions. In addition, the unique problems of the 64-line cardiac CT include the approximately $20 \mathrm{~s}$ single breath hold. Because the approximately $20 \mathrm{~s}$ breath hold may be difficult for patients with lung disease and/or older patients such as those more than significantly increases. Moreover, in accordance with the $\mathrm{CHADS}_{2}$ score, the positive predict values (PPVs) of MI in patients with SCS and UeCALs significantly increase $(p=0.003)$. The numbers of patients were $56,156,199,109,47$, and 32 for $\mathrm{CHADS}_{2}$ scores of 0 , $1,2,3,4$, and $\geq 5$ point(s), respectively

80 years old, the 320 -line cardiac CT scan, which has a shorter single breath hold time than the 64-line CT scan, may be more suitable for those older patients.

\section{Detection of myocardial ischemia by cardiac CT scans for RFCA of AF}

Although it has previously been reported that the relatively high prevalence of $\mathrm{CAD}$ in patients with $\mathrm{AF}$ who undergo RFCA of AF and its relation to $\mathrm{CHADS}_{2}$ score have already been reported using CAG [8], CAG may be more invasive than the cardiac CT. This study revealed that the cardiac CT for RFCA of AF at the timing of the image acquisition of LA-PVs could evaluate coronary artery lesions in $93 \%$ of the patients who underwent RFCA of AF. Finally, myocardial ischemia was detected in $9 \%$ of those patients by cardiac $\mathrm{CT}$ for RFCA of AF at the timing of the image acquisition of LA-PVs combined with the additional examinations including with exercise stress testing, ${ }^{201} \mathrm{Tl}$ scintigraphy, and/or fractionated flow reserve (FFR) measurements [12]. Moreover, a significant relationship between the $\mathrm{CHADS}_{2}$ score and myocardial ischemia (red bar in Fig. 1) $(p=0.003)$ was observed in this study. Furthermore, the positive predict value of myocardial ischemia in patients with severe coronary stenosis (>50\%) and unevaluable coronary artery lesions also significantly increased in accordance with the $\mathrm{CHADS}_{2}$ score (Fig. 1) $(p=0.003)$. These findings may support the previous findings that a high $\mathrm{CHADS}_{2}$ score has been proven to be a predictor of cardiovascular/cerebrovascular events in patients with documented CAD [4, 5]. Moreover, it has been reported that approximately $75 \%$ of culprit 
coronary artery lesions in patients who suffer from cardiovascular events such as acute coronary syndrome result from plaque ruptures developing a clot formation with mild-tomoderate coronary stenosis $[14,15]$. Because $24 \%$ of the patients with AF who underwent RFCA of AF had severe coronary stenosis $(>50 \%)$ in this study, the future cardiovascular event risk may be decreased by performing primary prevention using diet, exercise, optimal medical therapies including statins, and re-vascularization in those patients.

\section{Positive predict values of myocardial ischemia}

The positive predict values of myocardial ischemia in patients with severe coronary stenosis $(>50 \%)$ and unevaluable coronary artery lesions significantly increased in accordance with the $\mathrm{CHADS}_{2}$ score (Fig. 1) $(p=0.003)$. However, those values, especially in patients with less than 1 point with the $\mathrm{CHADS}_{2}$ score, were relatively low (17\%) compared with more than 4 points with that score (about $50 \%$ ). Moreover, it costs medical expenses for the additional examinations to evaluate myocardial ischemia. Thus, it is unknown whether it meets a law of nature to perform those examinations to evaluate myocardial ischemia in patients with severe coronary stenosis $(>50 \%)$ and unevaluable coronary artery lesions, even though their $\mathrm{CHADS}_{2}$ score is low.

\section{Limitations of the study}

Although our study was a multi-center trial, it was limited by the retrospective design and its relatively small number of patients. Patients with AF who did not undergo RFCA of $\mathrm{AF}$, especially with long-lasting $\mathrm{AF}$, were not included in this study. Thus, whether our results can safely be extrapolated to a larger number of patients including patients with AF who do not undergo RFCA of AF should be determined in further prospective studies.

\section{Conclusions}

This study revealed that both 64- and 320-line routine cardiac CT scans for RFCA of AF at the timing of the image acquisition of LA-PVs could be steadily detected coronary artery lesions. Moreover, the additional examinations combined with exercise stress testing, ${ }^{201} \mathrm{Tl}$ scintigraphy, and/or fractionated flow reserve (FFR) measurements [12] could precisely detect myocardial ischemia in $9 \%$ of patients with AF who underwent RFCA of AF. Thus, physicians should be aware of this condition when examining patients with $\mathrm{AF}$, especially in the presence of a high $\mathrm{CHADS}_{2}$ score, and that may be one of the most important risk factors for the progression of cardiovascular events in patients with AF. Finally, the evaluation of coronary artery lesions and myocardial ischemia by routine cardiac CT for RFCA of AF at the timing of the image acquisition of LA-PVs combined with the additional examinations including with exercise stress testing, ${ }^{201} \mathrm{Tl}$ scintigraphy, and/or fractionated flow reserve (FFR) measurements [12] may be one of the most feasible modalities for patients with AF.

Acknowledgements We thank Mr. John Martin for his linguistic assistance with this paper.

Funding None.

\section{Compliance with ethical standards}

\section{Conflict of interest None.}

Open Access This article is licensed under a Creative Commons Attribution 4.0 International License, which permits use, sharing, adaptation, distribution and reproduction in any medium or format, as long as you give appropriate credit to the original author(s) and the source, provide a link to the Creative Commons licence, and indicate if changes were made. The images or other third party material in this article are included in the article's Creative Commons licence, unless indicated otherwise in a credit line to the material. If material is not included in the article's Creative Commons licence and your intended use is not permitted by statutory regulation or exceeds the permitted use, you will need to obtain permission directly from the copyright holder. To view a copy of this licence, visit http://creativecommons.org/licenses/by/4.0/.

\section{References}

1. Piccini JP, Fauchier L (2016) Rhythm control in atrial fibrillation. Lancet 388:829-840

2. Gage BF, Waterman AD, Shannon W, Boechler M, Rich MW, Radford MJ (2001) Validation of clinical classification schemes for predicting stroke: results from the National Registry of Atrial Fibrillation. JAMA 285:2864-2870

3. Zuo ML, Liu S, Chan KH, Lau KK, Chong BH, Lam KF, Chan YH, Lau YF, Lip GY, Lau CP, Tse HF, Siu CW (2013) The CHADS2 and CHA 2DS 2-VASc scores predict new occurrence of atrial fibrillation and ischemic stroke. J Interv Card Electrophysiol 37:47-54

4. Tabata N, Yamamoto E, Hokimoto S, Yamashita T, Sueta D, Takashio S, Arima Y, Izumiya Y, Kojima S, Kaikita K, Matsui K, Fujimoto K, Sakamoto K, Shimomura H, Tsunoda R, Hirose T, Nakamura N, Sakaino N, Nakamura S, Yamamoto N, Matsumura T, Kajiwara I, Koide S, Sakamoto T, Nakao K, Oshima S, Tsujita K, Kumamoto Intervention Conference Study Investigators (2017) Prognostic value of the CHADS2 score for adverse cardiovascular events in coronary artery disease patients without atrial fibrillation-a multi-center observational cohort study. J Am Heart Assoc 6:e006355

5. Li Y, Wang J, Lv L, Xu C, Liu H (2018) Usefulness of the CHADS2 and R2CHADS2 scores for prognostic stratification in patients with coronary artery disease. Clin Interv Aging 13:565-571

6. Kawada S, Watanabe A, Morimoto Y, Nakagawa K, Nishii N, Nakamura K, Morita H, Ito H (2019) Radiofrequency catheter ablation prior to percutaneous coronary intervention in patients 
with atrial fibrillation coexisting with stable coronary artery disease: a single-center pilot study. Heart Vessels 34:632-640

7. Nucifora G, Schuijf JD, Tops LF, van Werkhoven JM, Kajander S, Jukema JW, Schreur JH, Heijenbrok MW, Trines SA, Gaemperli O, Turta O, Kaufmann PA, Knuuti J, Schalij MJ, Bax JJ (2009) Prevalence of coronary artery disease assessed by multislice computed tomography coronary angiography in patients with paroxysmal or persistent atrial fibrillation. Circ Cardiovasc Imaging 2:100-106

8. Tomomatsu T, Morishima I, Okumura K, Tsuboi H, Morita Y, Takagi K, Yoshida R, Nagai H, Ikai Y, Shibata N, Tsuzuki K, Sone T, Murohara T (2017) Comparison of frequency and characteristics of patients with atrial fibrillation having ablation with versus without coronary narrowing $(\geq 50 \%)$ by angiography. Am J Cardiol 119:1770-1775

9. Fuster V, Ryden LE, Cannom DS, Crijns HJ, Curtis AB, Ellenbogen KA, Halperin JL, Kay GN, Le Huezey JY, Lowe JE, Olsson SB, Prystowsky EN, Tamargo JL, Wann LS, Smith SC Jr, Priori SG, Estes NA 3rd, Ezekowitz MD, Jackman WM, January CT, Lowe JE, Page RL, Slotwiner DJ, Stevenson WG, Tracy CM, Jacobs AK, Anderson JL, Albert N, Buller CE, Creager MA, Ettinger SM, Guyton RA, Halperin JL, Hochman JS, Kushner FG, Ohman EM, Stevenson WG, Tarkington LG, Yancy CW, American College of Cardiology Foundation/American Heart Association Task F (2011) 2011 ACCF/AHA/HRS focused updates incorporated into the ACC/AHA/ESC 2006 guidelines for the management of patients with atrial fibrillation: a report of the American College of Cardiology Foundation/American Heart Association Task Force on practice guidelines. Circulation 123:e269-367

10. Kistler PM, Rajappan K, Jahngir M, Earley MJ, Harris S, Abrams D, Gupta D, Liew R, Ellis S, Sporton SC, Schilling RJ (2006) The impact of CT image integration into an electroanatomic mapping system on clinical outcomes of catheter ablation of atrial fibrillation. J Cardiovasc Electrophysiol 17:1093-1101

11. Mori S, Endo M, Asakura H (2006) Improvement in banding artefacts in four-dimensional computed tomography for radiotherapy planning. Phys Med Biol 51:5231-5244

12. De Bruyne B, Fearon WF, Pijls NH, Barbato E, Tonino P, Piroth Z, Jagic N, Mobius-Winckler S, Rioufol G, Witt N, Kala P, MacCarthy P, Engstrom T, Oldroyd K, Mavromatis K, Manoharan G, Verlee P, Frobert O, Curzen N, Johnson JB, Limacher A, Nuesch E, Juni P, Investigators FT (2014) Fractional flow reserve-guided PCI for stable coronary artery disease. N Engl J Med 371:1208-1217

13. Jarvinen V, Uusitalo V, Tolvanen T, Saraste A, Kuusisto J, Sinisalo J, Knuuti J (2018) The accuracy of left ventricular and left atrial volumetry using 64-slice computed tomography. In vitro validation study with human cardiac cadaveric casts. J Comput Assist Tomogr 42:754-759

14. Fuster V, Badimon L, Badimon JJ, Chesebro JH (1992) The pathogenesis of coronary artery disease and the acute coronary syndromes (2). N Engl J Med 326:310-318

15. Fuster V, Badimon L, Badimon JJ, Chesebro JH (1992) The pathogenesis of coronary artery disease and the acute coronary syndromes (1). N Engl J Med 326:242-250

Publisher's Note Springer Nature remains neutral with regard to jurisdictional claims in published maps and institutional affiliations. 